\title{
Antioxidant Effects of Methanol Extract of Dracocephalum kotschyi in Acetic Acid Induced Rat Colitis Model
}

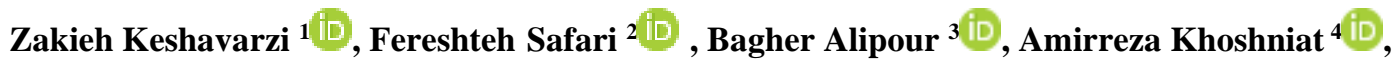 \\ Reza Azizi ${ }^{4}$, Mehran Vatanchian 1 (D), Fatemeh Maghool ${ }^{* *}$ (iD
}

1. Natural Products and Medicinal Plants Research Center, North Khorasan University of Medical Sciences, Bojnurd, Iran

2. Dept. of Physiology and Pharmacology, North Khorasan University of Medical Sciences, Bojnurd, Iran

3. Dept. of Molecular and Cellular Biology, Faculty of Basic Science, University of Mazandaran, Mazandaran, Iran

4. Student Research Committee, School of Medicine, North Khorasan University of Medical Sciences, Bojnurd, Iran

5. Poursina Hakim Digestive Diseases Research Center, Isfahan University of Medical Sciences, Isfahan, Iran

\begin{tabular}{|c|}
\hline Article Info \\
\hline doi $\underline{10.30699 / j a m b s .30 . e 56821}$ \\
\hline $\begin{array}{l}\text { Received: 2020/10/12; } \\
\text { Accepted: 2021/01/25; } \\
\text { Published Online: } 17 \text { Nov 2021; }\end{array}$ \\
\hline $\begin{array}{l}\text { Use your device to scan and read the } \\
\text { article online }\end{array}$ \\
\hline 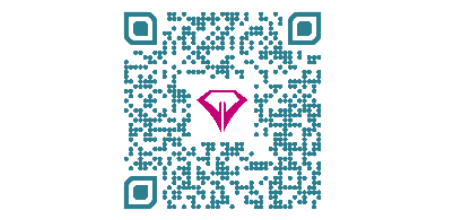 \\
\hline Article URL: Link \\
\hline $\begin{array}{l}\text { Corresponding Information: } \\
\text { Fatemeh Maghool, } \\
\text { Poursina Hakim Digestive Diseases } \\
\text { Research Center, Isfahan University } \\
\text { of Medical Sciences, Isfahan, Iran. } \\
\text { E-Mail: } \\
\text { fmaghool@gmail.com }\end{array}$ \\
\hline
\end{tabular}

ABSTRACT

Background \& Objective: There is a worldwide trend towards substitute synthetic antioxidants with natural alternatives to treat inflammatory bowel disease (IBD) such as ulcerative colitis (UC). This study was conducted to evaluate the effects of Dracocephalum kotschyi extract on tissue injury and oxidative stress in an aceticacid induced colitis model.

Materials \& Methods: 48 male Wistar rats were allocated to 6 groups: healthy control, colitis control, and 4 treatment groups which administrated 10, 25, and 50 $\mathrm{mg} / \mathrm{kg}$ of $D$. kotschyi extract respectively, and $200 \mathrm{mg} / \mathrm{kg}$ sulfasalazine once daily for 8 days after colitis induced. Colitis severity was assessed using histologic and macroscopic changes of damaged colon, and enzymatic antioxidant activities like superoxide dismutase (SOD), total thiol (-SH), superoxide dismutase (SOD), and lipid peroxidation marker MDA (malondialdehyde) were evaluated.

Results: D. kotschyi extract $(50 \mathrm{mg} / \mathrm{kg})$ decreased colonic macroscopic and histological damage scores, which were accompanied by a significant decrease in lipid peroxidation, and an increase in colonic antioxidant markers.

Conclusion: The results suggest that D. kotschyi extract is effective against oxidative bowel damages induced in IBD and its beneficial effect is, at least in part, due to its antioxidant properties.

Keywords: Colitis, Oxidative stress, Herbal medicine, Inflammatory bowel disease

fmaghool@gmail.com

\section{Introduction}

Ulcerative colitis (UC) is a kind of inflammatory bowel disease (IBD) characterized by relapsing-remitting courses that affect millions of people worldwide, giving rise to a wide variety of symptoms and signs that impair quality of life and ability to function (1). UC is difficult to treat because of its complex etiology. Most current treatments for UC comprise treatment with glucocorticosteroids, sulfasalazine (SSZ), and 5-aminosalicylic acid (2). However, because of adverse reactions during prolong treatment with these agents, effective drugs with fewer side effects should be developed.

Since high levels of lipid peroxidation products and reactive oxygen species (ROS) have been reported in colorectal biopsy specimens of IBD patients, particular attention has been given to the role of free radicals in the pathogenesis of UC (3). A limited amount of glutathione peroxidase (GPx) and superoxide dismutase (SOD) as antioxidant enzymes has been evidenced in colonic tissue. In IBD, important sources of ROS in inflammatory tissue, such as neutrophils and active leukocytes, are able to produce large amounts of ROS that can cause cell-membrane damage and eventually cell death (4). Therefore, a disturbance in the prooxidant-antioxidant balance may be important in the initiation and maintenance of tissue injury in UC. (5).

During recent years, a worldwide trend has been developing to substitute synthetic antioxidants with natural alternatives extracted from plant sources.

The name "badrashbi" has been used for various species of Dracocephalum (Labiatae) in Iran (6). Dracocephalum kotschyi (also called Zarrin-giah), is one 
of the Lamiaceae species, that is mostly distributed in south-west Asian countries, including Iran (7).

The essential oil composition of this plant was analyzed by Yaghmaii et al. for the first time (8). Traditionally, D. kotschyi has been used for treating different pathological conditions such as headache, congestion, and gastrointestinal disorders (9). It has also been used for its antispasmodic and analgesic properties in Iranian folk medicine. During that last decade, various pharmacological activities have also been attributed to this plant including antihyperlipidemic, cytotoxic, antinociceptive, and immunomodulatory effects (1012). It has been revealed that $D$. kotschyi contains several phenolic and terpenoid compounds, such as luteolin, apigenin, isokaempferide, $\alpha$-terpineol, xanthomicrol, cirsimaritin, and rosmarinic acid, and these components suggested to have various anti-cancer, antiinflammatory, as well as antioxidant properties $(13,14)$. However, the antioxidant effects of $D$. kotschyi on UC have not yet been studied.

Acetic acid-induced colitis (AA-induced colitis) is a well-established and repeatable experimental model of UC, sharing many histopathological and biochemical characteristics with human colitis (15). The present study was undertaken to evaluate the tissue damage and oxidative stress in the rat model of UC, and the effect of D. kotschyi on this oxidant-mediated disorder, to set up a possible basis for the treatment of UC.

\section{Materials and Methods}

\section{Plant material}

D. kotschyi leaves (Fig. 1) were collected from the North Khorasan Province of Iran and dried under shade and at room temperature $\left(25^{\circ} \mathrm{C}\right)$, and using an electric grinder (Moulinex, France), grounded into a powder and passed through a 60 -mesh sieve. About $100 \mathrm{~g}$ of sample was macerated in $96 \%$ alcohol (methanol) for $48 \mathrm{~h}$. Then the extraction was concentrated using rotary vacuum, and the different concentrations of that were prepared.

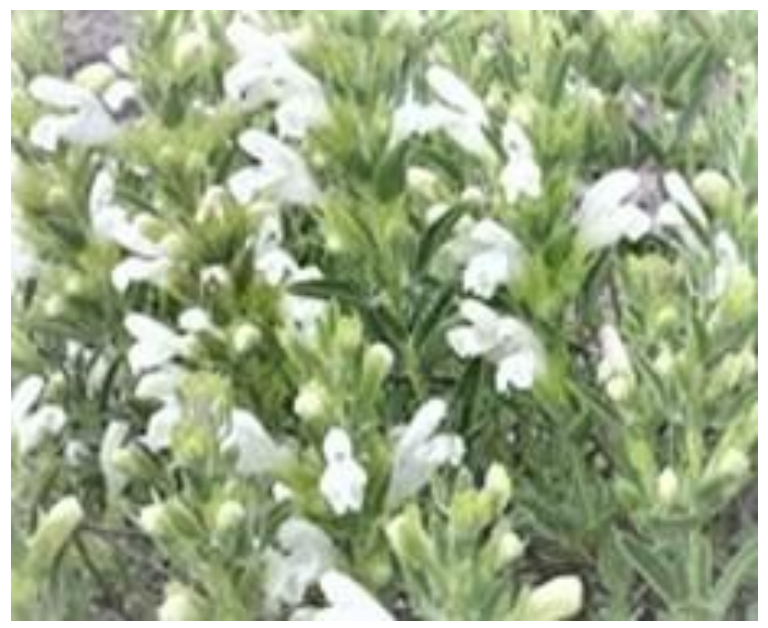

Figure 1: Aerial parts of Dracocephalum kotschyi Animals
48 male Wistar rats weighing 200-250 g were used in this study. The rats were kept under controlled conditions (temperature $22 \pm 2{ }^{\circ} \mathrm{C}$ and 12-h light and dark cycle) and allowed free access to water and rat chow. All protocols were reviewed and approved by the ethical committee (IR.UMZ.REC.1397.022) of North Khorasan (Bojnurd) University of Medical Sciences, according to "Guide for the Care and Use of Laboratory Animals" (NRCotN, 2011).

\section{Colitis induction}

Under light ether anesthesia (16), a polyethylene cannula (long: $80 \mathrm{~mm}, 2 \mathrm{~mm}$ outer diameter) was inserted into the rat colon, and then $2 \mathrm{ml}$ of AA (3\% v/v in $0.9 \%$ saline) was injected - into the colon. Healthy control rats administrated the same volume of $0.9 \%$ saline solution. The rats were allocated into the 6 groups $(n=8)$. Group I (healthy control group) received saline, intraperitoneally (IP); group II (colitis) received $2 \mathrm{ml}$ of $3 \% \mathrm{AA}$, intrarectally; Groups III, IV, V, and VI (treatment groups): colitis induced rats received treatments ( $D$. kotschyi extract at the doses of 10,25 , and $50 \mathrm{mg} / \mathrm{kg} / \mathrm{day}$ (IP), respectively, and SSZ (200 mg/kg, IP), for 8 days after colitis induced.

\section{Macroscopic Scoring}

Colon sections were examined macroscopically by a blinded experienced pathologist. According to a scale ranging from 0 to 4 , colonic mucosa macroscopic appearance was scored in the following manner: (0) without macroscopic changes, (1) erythema of mucosa, (2) mild edema of the mucosa, small erosions, (3) moderate edema, erosions or bleeding ulcers and (4) severe tissue ulceration or necrosis (17).

\section{Histopathological Study}

Samples of colon were stained with hematoxylin and eosin for histological examination. The sections were studied, analyzed and photographed using the Olympus CX41 monitoring system. The histopathologic analysis was evaluated using the Bita2012 scoring system, and comparison among the groups was done based on 10 different parameters. These parameters include crypts architecture, lymphoplasmacytic, cryptitis, ulcers, lamina propria eosinophils, ulcers, granulomas, paneth cell metaplasia, lymphoid nodules at the base, muscularis mucosae hyperplasia, and endocrine cell hyperplasia. Scores of 2,1, and 0 points were given according to the severity of the induced damage from severe, medium, to none, respectively, and the total score of histological changes ranged from 0 to 17 points.

\section{Biochemical analysis}

Total thiol (-SH) groups assay was based on the reduction of DTNB (5,50-dithiobis-2-nitrobenzoic acid) by thiols to produce a derivative (TNB) with a peak absorbance of $412 \mathrm{~nm}$ (18). Briefly, Tris-EDTA buffer containing EDTA was added to colon tissue homogenate and the absorbance was read at $412 \mathrm{~nm}$ (A1). Then, after adding $20 \mu 1$ of DTNB reagents to the mixture, the sample absorbance was read again after $15 \mathrm{~min}(\mathrm{~A} 2)$. The 
Absorbance of DTNB reagent was also read as a blank (B). The total thiol concentration ( $\mathrm{mM})$ was calculated according to the following equation: (A2-A1-B) * $1.07 / 0.05 * 13.6(19)$.

MDA (malondialdehyde) levels were measured by the method of Ohkawa et al. for assessing the lipid peroxidation (20). In this method, an aliquot of the tissue homogenate was added to thiobarbituric acid (TBA). The mixture was boiled for $45 \mathrm{~min}$ at $100{ }^{\circ} \mathrm{C}$. After cooling, samples were centrifuged for $15 \mathrm{~min}(3000 \mathrm{rpm})$. Finally, the absorbance of the stained product present in the supernatant was read (wavelength $=535 \mathrm{~nm}$ ) and compared with a curve made by MDA standards. The concentration of obtained TBARS was expressed in $\mathrm{nmol} / \mathrm{g}$ protein.

The activity of glutathione peroxidase (GPx) in homogeneous tissue was assessed using the standard kit (ZellBio GmbH, Ulm, Germany), according to the kit protocol, and was read at $412 \mathrm{~nm}$ through the colorimetric method.

Superoxide dismutase (SOD) activity was evaluated by an enzymatic assay kit (ZellBio GmbH, Ulm, Germany). The quantity of the sample that catalyzed breakdown of $1 \mu \mathrm{mol}$ of $\mathrm{O}^{2-}$ into $\mathrm{H}_{2} \mathrm{O}_{2}$ and $\mathrm{O}_{2}$ per minute was considered as SOD activity. Absorbance was recorded at $420 \mathrm{~nm}$ and expressed as units per milligram of colon protein.

\section{Gastric acid measurement}

Through an incision in the pyloric region, a catheter was passed into the stomach for measuring gastric acid output, and the animals were allowed $30 \mathrm{~min}$ for stabilization. After the stabilization time, $1 \mathrm{ml}$ of a solution of $0.9 \%$ $\mathrm{NaCl}$ w/v (saline) was perfused into the stomach and discarded after $15 \mathrm{~min}$. After the next $\mathrm{NaC} 1$ perfusion, the second 15 min gastric secretions collection was used for basal secretion values. The acid content of the samples was measured using a manual titrator and the results were expressed as $\mathrm{mEq} / \mathrm{ml} / 15 \mathrm{~min}(21)$.

\section{Statistical analysis}

The statistical significance of differences among various groups was determined using one-way analysis of variance (ANOVA) followed by Tukey's test. P values less than 0.05 were considered significant. The results were expressed as mean \pm standard error of the mean.

\section{Results}

\section{Macroscopic and Histopathologic Assessment of Colitis}

Intrarectal instillation of acetic acid produced striking macroscopic signs of colitis D. kotschyi $(50 \mathrm{mg} / \mathrm{kg})$ and sulfasalazine treated groups both had significantly reduced damage scores $(\mathrm{p}<0.01)$ in comparison to the non-treated colitis group. This effect was slightly less pronounced in the other treated groups (10 and $25 \mathrm{mg} / \mathrm{kg}$ of D. kotschyi) (Fig. 2). Figure. 3 illustrates the changes in the large intestine histology of different experimental groups. Inflammatory responses were detected eight days after the AA administration in colitis rats, characterized by loss of colonic crypts and epithelium, and submucosal edema (Fig. 3B). Whereas, these changes did not occur in healthy controls (Fig. 3A). Treatment with D. kotschyi (50 $\mathrm{mg} / \mathrm{kg}$ ) effectively reduced the intensity of the histological signs of colonic tissue injury and markedly decreased the colonic ulcer score (Fig. 3E).

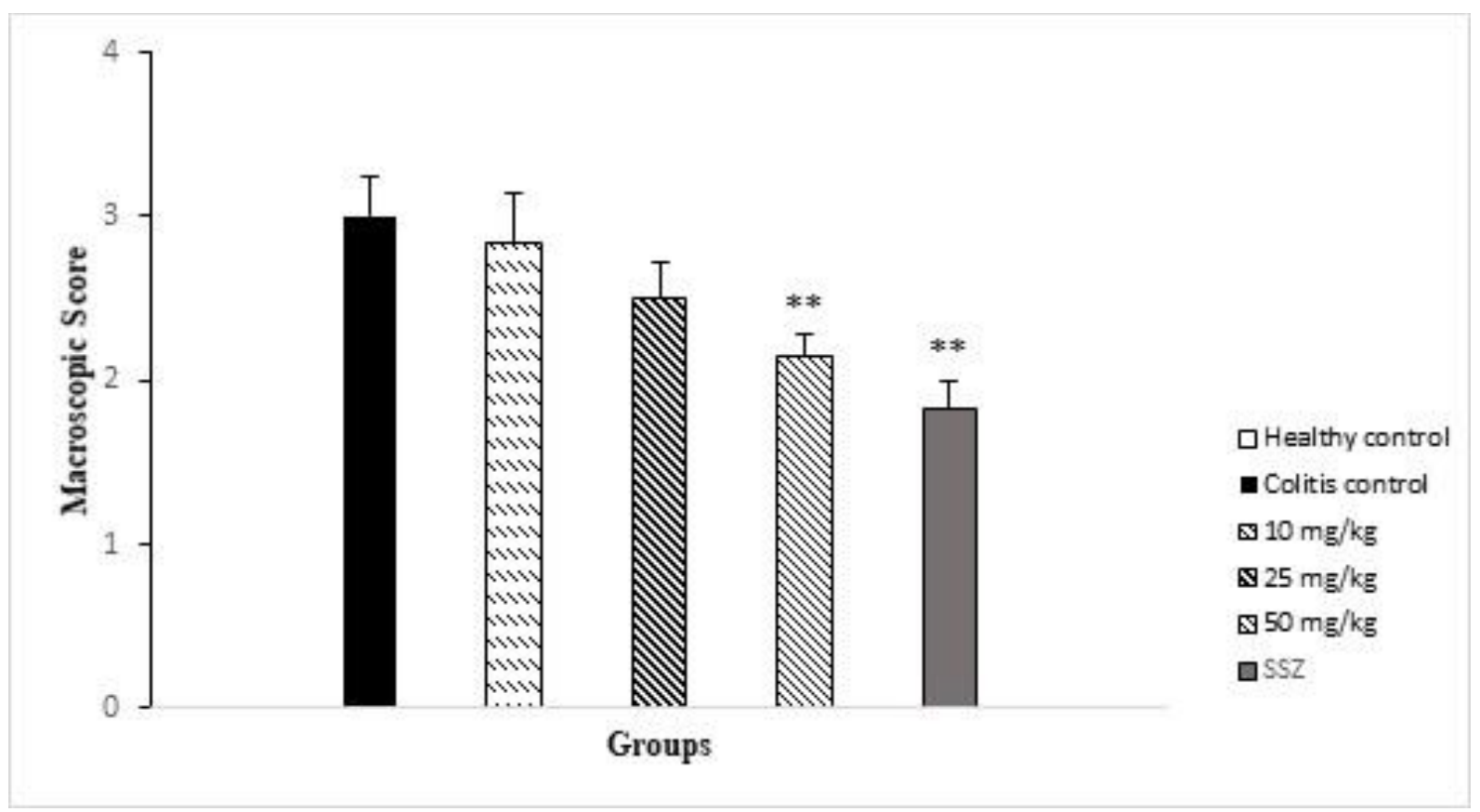

Figure 2: The effect of 3 different doses of $D$. kotschyi methanol extracts on colonic damage score in colitis rats compared with healthy control and colitis control groups. $* *$ * $<0.001$ and $* * p<0.01$ vs. colitis control. Data are expressed as means \pm SEM. 


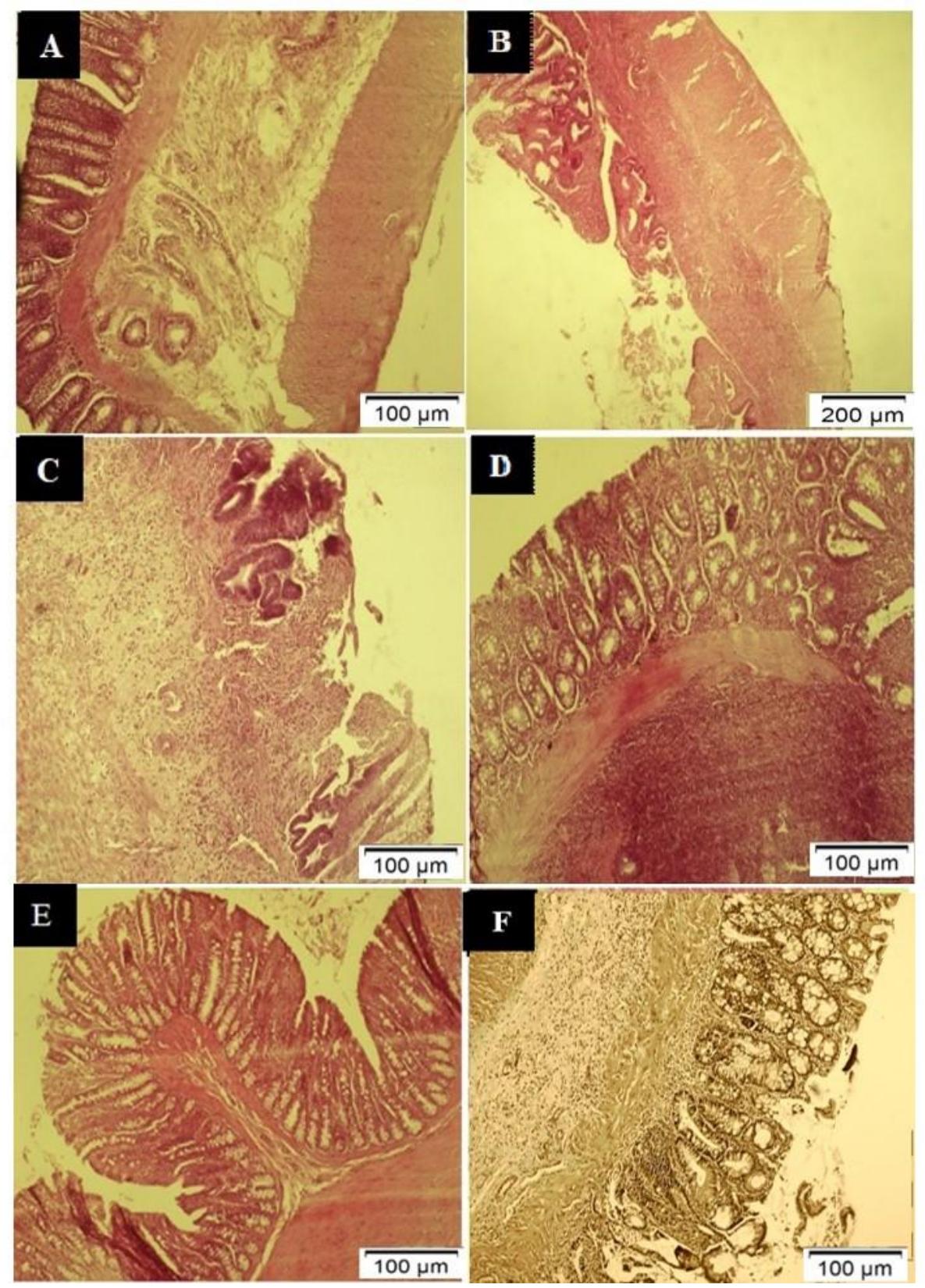

Figure 3: The histological changes of colonic tissue in different experimental groups. (A) The regular arrangement of crypts is evident in the mucous membrane, submucosa and muscle wall of the colon in healthy conditions $(\mathrm{H} \& \mathrm{E}, \times 400)$. (B) Mucosal ulceration and architectural changes including crypt loss and crypt distortion (arrow) after colitis induction (H\&E, $\times$ 100). (C) Minimal mucosal change after 8 days of treatment with D. kotschyi $(10 \mathrm{mg} / \mathrm{kg})(\mathrm{H} \& \mathrm{E}, \times 400)$. (D) Crypt regeneration with mild crypt distortion after treatment with D. kotschyi $(25 \mathrm{mg} / \mathrm{kg})(\mathrm{H} \& \mathrm{E}, \times 400)$. (E) The natural arrangement of crypts and the removal of active inflammatory infiltrate in the colon wall represents a significant improvement with treatment of $D$. kotschyi $(50 \mathrm{mg} / \mathrm{kg})(\mathrm{H \& E}, \times 400)$. (F) Absence of significant active inflammation, intact surface and glandular epithelial cells and minimal architectural distortion are evident of histological remission with sulfasalazine $(\mathrm{H} \& \mathrm{E}, \times 400)$.

\section{Biochemical assays}

Colonic MDA level showed a significant increase in colitis control compared with that in the healthy control rats ( $p<0.001$, Fig. 4). Some changes were observed in colonic MDA content between colitis control and 10 $\mathrm{mg} / \mathrm{kg}$ D. kotschyi extract-treated group. MDA levels were significantly reduced in the groups that received 25 and $50 \mathrm{mg} / \mathrm{kg}$ of $D$. kotschyi extract, as well as $200 \mathrm{mg} / \mathrm{kg}$ of SSZ.
As depicted in Fig. 5, total thiol content decreased significantly after colitis induction ( $\mathrm{p}<0.001)$. Treatment with D. kotschyi $(50 \mathrm{mg} / \mathrm{kg})$ induced a striking increase in total thiol content $(\mathrm{p}<0.01)$ in comparison to the colitis group. Furthermore, administration of D. kotschyi (25 $\mathrm{mg} / \mathrm{kg}$ ) and sulfasalazine protected against colonic total thiol depletion induced by acetic acid ( $\mathrm{p}<0.05)$.

The activity of the antioxidant enzyme SOD in the AAinduced colitis group decreased significantly $(p<0.05$ vs. 
the healthy control rats). The decrease observed in the control colitis has a trend to increase by the treatments with $D$. kotschyi extract at the dose of $50 \mathrm{mg} / \mathrm{kg}$, as well as SSZ as shown in Table. 1. Results also revealed that the

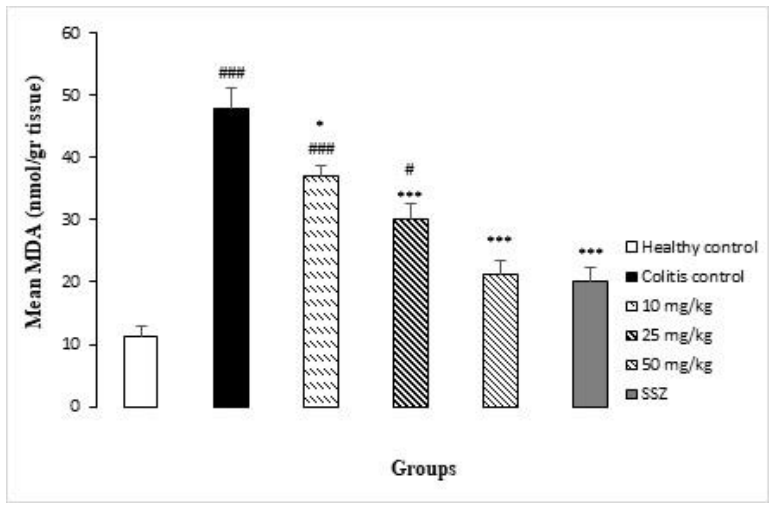

Figure 4: Effects of 3 different doses of D. kotschyi methanol extract and sulfasalazine (SSZ) on colonic MDA levels of colitis rats compared with healthy control and colitis control (CC) groups. *p $<0.05$, ***p $<0.001$ vs. colitis control; \#P $<0.05$, \#\# $\quad<0.001$ vs. healthy control. Data are expressed as means \pm SEM. activity of GPx significantly ( $\mathrm{p}<0.001$ ) declined in AAtreated animals in comparison to healthy control ones, whereas treatment with D. kotschyi ( $50 \mathrm{mg} / \mathrm{kg}$ ) and SSZ increased the GPx activity to normal levels.

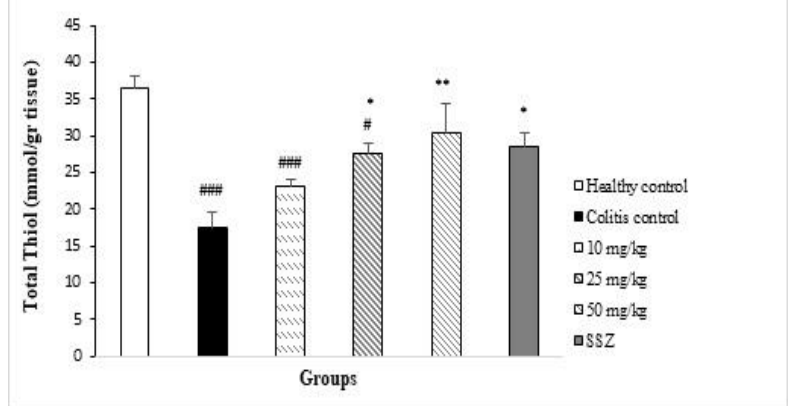

Figure 5: Effects of 3 different doses of D. kotschyi methanol extract and sulfasalazine (SSZ) on total thiol content in colonic tissue of colitis rats compared with healthy control and colitis control groups. *p $<0.05$, **p $<0.01$ vs. colitis control; \#p $<0.05$ and \#\#\#p $<0.001$ vs. healthy control. Data are expressed as means \pm SEM.

Table 1: Effects of various doses of D. kotschyi extract and sulfasalazine (SSZ) on colonic SOD and GPx activity in colitis rats compared with healthy and colitis control groups.

\begin{tabular}{|c|c|c|c|c|c|c|}
\hline Groups & Healthy control & Colitis control & $\begin{array}{l}\text { D. kotschyi } \\
\text { (10 mg/kg) }\end{array}$ & $\begin{array}{l}\text { D. kotschyi } \\
\text { (25mg/kg) }\end{array}$ & $\begin{array}{l}\text { D. kotschyi } \\
\text { (50 mg/kg) }\end{array}$ & SSZ \\
\hline $\begin{array}{l}\text { SOD } \\
(\mathrm{u} / \mathrm{mg})\end{array}$ & $42.62 \pm 2.8$ & $29.93 \pm 3^{\#}$ & $30.29 \pm 1.8 \#$ & $33.45 \pm 1.7$ & $39.06 \pm 4.3$ & $40.22 \pm 7.2$ \\
\hline $\begin{array}{l}\text { GPx } \\
(\mathrm{u} / \mathrm{mg})\end{array}$ & $359.4 \pm 34.1$ & $136.3 \pm 21.8^{\# \#}$ & $210.7 \pm 99.4 \# \#$ & $225 \pm 10.6$ & $306.7 \pm 23^{* *}$ & $276.7 \pm 25^{*}$ \\
\hline
\end{tabular}

\section{Acid secretion}

Basal acid secretion in the healthy control rats averaged $7.2 \pm 1.8 \mathrm{mEq} / \mathrm{ml} / 15 \mathrm{~min}$ period. In the rats in which colitis had been induced with acetic acid, basal acid secretion has a trend to increase but it was not statistically significant (data are not shown). D. kotschyi extract administration to the colitis rats did not induce any significant change in gastric acid secretion.

\section{Discussion}

The present study revealed that $D$. kotschyi induced improvements in various inflammatory parameters in an acetic acid-induced colitis model, which were shown through macroscopic, histological, and biochemical changes. Previous models of AA-induced colitis have been used for screening active drugs against inflammatory bowel disease and chemical phenomena related to the production of free radicals (22). In inflammatory conditions such as colitis, the natural balance between ROS production and the protective effect of free radical scavengers may be disturbed and resulted in tissue damage (23). Disturbed tissue protection makes the cells predispose to oxidative injury, which may contribute to the progression of the damage observed in experimental models of colitis (19). Therefore, increased oxidative stress and an impaired antioxidant defense likely play a role in UC pathogenesis.

Antioxidant enzymes such as SOD and GPx protect tissues against oxidative damage. Disorders in antioxidant defense system have been reported after colonic inflammation (24). The increase in tissue lipid peroxidation triggers a defective cycle that produces more and more metabolites that exhaust the antioxidant system of the cell and cause more inflammation (25). Therefore, it is logical to assume that treatment with $D$. kotschyi can improve the oxidative stress observed in experimental colitis because it reduced the MDA levels, which is an indicator of lipid peroxidation (24). In our study, MDA levels were reduced in treatment groups parallel to the macroscopic and histological changes. The decrease was more evident in D. kotschyi $(50 \mathrm{mg} / \mathrm{kg})$ and SSZ rats. These results suggest that $D$. 
kotschyi may have beneficial effects by reducing lipid peroxidation in damaged tissues of colon.

Sulfhydryl (SH), high-reactive components of protein molecules, are essential free radicals scavengers (26). It has revealed that $\mathrm{SH}$ groups are sensitive to oxidative injury and deplete after colitis induction (24). Our study showed a decrease in total sulfhydryl groups following the induction of colitis. Considering that the higher $\mathrm{SH}$ contents were observed in $D$. kotschyi treated rats than their respective control group, it is reasonable to suggest that $D$. kotschyi helped to replenish the total thiol pool.

One of the other important antioxidative defense mechanisms present in tissues is glutathione metabolism, which diminution that accelerates colon damages due to oxidative stress (25). In the current study, the data showed that GPx activity significantly decreased in control colitis group and treatment with $D$. kotschyi $(50 \mathrm{mg} / \mathrm{kg})$ restored that to the normal levels, suggesting an antioxidant effect of this plant. Therefore, an increase in colonic GPx activity may explain some of the beneficial effects of $D$. kotschyi in experimental colitis.

There are some reports of reduction of SOD activity in different studies as a result of oxidative stress (27). Superoxide anions can be catalyzed to $\mathrm{H} 2 \mathrm{O} 2$ by scavenging the activity of SOD. In the present study, acetic acid administration reduced the SOD activity, which indicates the generation of reactive species $(20,27$, 28), but no change in SOD activity was seen after the administration of $D$. kotschyi extract.

It has been shown that the $D$. kotschyi extract has a high amount of flavonoid and phenolic compounds, which have shown the highest antioxidant activity, and are probably responsible for the antioxidant activity of this plant $(29,30)$. The antioxidant activity can be mostly attributed to phenolic compounds such as luteolin, apigenin, xanthomicrol, rosmarinic acid and cirsimaritin in extracts of $D$. Kotschyi $(31,32)$. Phenolic compounds have redox potentials, which allow them to act as hydrogen donors and singlet oxygen quenchers.

The result of the present study showed that $D$. kotschyi extract exhibited antioxidant activity possibly through the modulation of antioxidant enzymes (GPx, and total thiol) as well as the suppression of lipid peroxidation. The findings of the current investigation support this notion that some medicinal plants are rich sources of natural antioxidants and flavonoids and could be used as therapeutic agents for some inflammatory diseases.

Since some studies have reported that chronic active gastritis is a common finding in patients with UC (33), we also performed a gastric acid secretion assay in our study. No change in basal gastric acid secretion was documented after colitis induction. Although a direct connection has been shown between the inflammation noted in the rectum and the stomach of IBD patients (34), the mechanisms underlying are poorly understood. Our results where consistent with the findings of some other studies (17), where no change in gastric acid secretion was shown after experimental colitis, which may suggest other contributing mechanisms in gastritis concomitant with the colitis.

\section{Conclusion}

In conclusion, our data indicate that the methanol extract of Dracocephalum kotschyi may diminish the colonic mucosal damage in experimental colitis by enhancing the activities of antioxidant enzymes and oxidative stress markers such as GPx and total thiol and by reducing the MDA (an oxidant indicator) level. Further investigations to clarify the mechanism of action of this plant extract is warranted.

\section{Acknowledgment}

A special thanks to Dr. Elham Amjadi for her technical assistance. Authors are also grateful to the Research Deputy of North Khorasan University of medical sciences for financial support to carry out this work.

\section{Conflicts of Interest}

There is no conflict of interest.

\section{References}

1. Colitis-Pathophysiology U. Inflammatory bowel disease part I: ulcerative colitis-pathophysiology and conventional and alternative treatment options. Altern Med Rev. 2003;8(3):247-83.

2. Podolsky DK. Inflammatory bowel disease. N Engl J Med. 1991;325(14):1008-16. [DOI:10.1056/NEJM199110033251406] [PMID]

3. Lih-Brody L, Powell SR, Collier KP, Reddy GM, Cerchia R, Kahn E, et al. Increased oxidative stress and decreased antioxidant defenses in mucosa of inflammatory bowel disease. Dig Dis Sci. 1996;41(10):2078-86. [DOI:10.1007/BF02093613] [PMID]

4. Zhou G, Yu L, Fang L, Yang W, Yu T, Miao Y, et al. CD177+ neutrophils as functionally activated neutrophils negatively regulate IBD. Gut. 2018;67(6):1052-63. [DOI:10.1136/gutjnl-2016313535] [PMID]

5. Mulder T, Verspaget H, Janssens A, De Bruin P, Pena A, Lamers C. Decrease in two intestinal copper/zinc containing proteins with antioxidant function in inflammatory bowel disease. Gut. 1991;32(10):1146. [DOI:10.1136/gut.32.10.1146] [PMID] [PMCID]

6. Mirheidar H. Knowledge of plants. Amir kabir, Tehran. 1995.

7. Naghibi F, Mosaddegh M, Mohammadi Motamed M, Ghorbani A. Labiatae family in folk medicine in Iran: from ethnobotany to pharmacology. IJPR. 2010:63-79. 
8. Yaghmai MS, Taffazoli R. The essential oil of Dracocephalum kotschyi Boiss. Flavour Fragr J. 1988;3(1):33-6. [DOI:10.1002/ffj.2730030107]

9. Kamali M, Khosroyar S, Mohammadi A. Antibacterial activity of various extracts from Dracocephalum kotschyi against food pathogenic microorganisms. Int $\mathbf{J}$ Pharmtech Res. 2015;8(9):158-63.

10. Amirghofran $\mathrm{Z}$, Azadbakht $\mathrm{M}$, Karimi $\mathrm{MH}$. Evaluation of the immunomodulatory effects of five herbal plants. J Ethnopharmacol. 2000;72(1):167-72. [DOI:10.1016/S03788741(00)00234-8]

11. Golshani S, Karamkhani F, Monsef-Esfehani HR, Abdollahi M. Antinociceptive effects of the essential oil of Dracocephalum kotschyi in the mouse writhing test. J Pharm Sci. 2004;7:76-9.

12. Jahaniani F, Ebrahimi SA, Rahbar-Roshandel N, Mahmoudian M. Xanthomicrol is the main cytotoxic component of Dracocephalum kotschyii and a potential anti-cancer agent. Phytochemistry. 2005;66(13):1581-92.

[DOI:10.1016/j.phytochem.2005.04.035] [PMID]

13. Park CM, Jin K-S, Cho CW, Lee Y-W, Huh G-H, Cha Y-S, et al. Luteolin inhibits inflammatory responses by downregulating the JNK, NF- $\kappa \mathrm{B}$, and AP-1 pathways in TNF- $\alpha$ activated HepG2 cells. Food Sci Biotechnol. 2012;21(1):279-83. [DOI:10.1007/s10068-012-0037-x]

14. Jang S, Kelley KW, Johnson RW. Luteolin reduces IL-6 production in microglia by inhibiting JNK phosphorylation and activation of AP-1. PANS. 2008;105(21):7534-9.

[DOI:10.1073/pnas.0802865105] [PMID] [PMCID]

15. MacPherson B, Pfeiffer C. Experimental production of diffuse colitis in rats. Digestion. 1978;17(2):135-50. [DOI:10.1159/000198104] [PMID]

16. El-Naggar ME, Hussein J, El-sayed SM, Youssef AM, El Bana M, Latif YA, et al. Protective effect of the functional yogurt based on Malva parviflora leaves extract nanoemulsion on acetic acidinduced ulcerative colitis in rats. JMRT. 2020;9(6):14500-8.

[DOI:10.1016/i.jmrt.2020.10.047]

17. Langmead L, Dawson C, Hawkins C, Banna N, Loo S, Rampton D. Antioxidant effects of herbal therapies used by patients with inflammatory bowel disease: an in vitro study. Aliment Pharmacol Ther. 2002;16(2):197-205. [DOI:10.1046/j.1365-2036.2002.01157.x] [PMID]

18. Keshavarzi Z, Nurmohammadi F, Majlesi S, Maghool F. Protective effects of walnut extract against oxidative damage in acetic acid-induced experimental colitis rats. Physiology and Pharmacology. 2019;23(1):51-8.

19. Keshavarzian A, Sedghi S, Kanofsky J, List T, Robinson C, Ibrahim C, et al. Excessive production of reactive oxygen metabolites by inflamed colon: analysis by chemiluminescence probe. Gastroenterology. 1992;103(1):177-85. [DOI:10.1016/0016-5085(92)91111-G]

20. Ohkawa H, Ohishi N, Yagi K. Assay for lipid peroxides in animal tissues by thiobarbituric acid reaction. Anal Biochem. 1979;95(2):351-8. [DOI:10.1016/0003-2697(79)90738-3]

21. Alikhani V, Keshavarzi Z, Hadjzadeh MAR, Karimi S. The Effect of Melatonin on Gastric Parameters Following Diabetes Induction in Male Rats. Acta Endocrinol (Copenh). 2015;11(2). [DOI:10.4183/aeb.2015.155]

22. Carty E, De Brabander M, Feakins R, Rampton D. Measurement of in vivo rectal mucosal cytokine and eicosanoid production in ulcerative colitis using filter paper. Gut. 2000;46(4):487-92. [DOI:10.1136/gut.46.4.487] [PMID] [PMCID]

23. Blau S, Rubinstein A, Bass P, Singaram C, Kohen $\mathrm{R}$. Differences in the reducing power along the rat GI tract: lower antioxidant capacity of the colon. Mol Cell Biochem. 1999;194(1-2):185-91. [DOI:10.1023/A:1006994800272] [PMID]

24. Harisa GEI, Abo-Salem OM, El-Sayed E-SM, Taha EI, El-Halawany N. L-arginine augments the antioxidant effect of garlic against acetic acidinduced ulcerative colitis in rats. Pak J Pharm Sci. 2009;22(4).

25. Hagar HH, El Medany A, El Eter E, Arafa M. Ameliorative effect of pyrrolidinedithiocarbamate on acetic acid-induced colitis in rats. Eur J Pharmacol 2007:554(1):69-77. [DOI:10.1016/j.ejphar.2006.09.066] [PMID]

26. Del Maestro R. An approach to free radicals in medicine and biology. Acta Physiol Scand Suppl. 1980;492:153-68.

27. Guan G, Lan S. Implications of antioxidant systems in inflammatory bowel disease. Biomed Res Int. 2018;2018. [DOI:10.1155/2018/1290179] [PMID] [PMCID]

28. Biswas S, Das R, Banerjee ER. Role of free radicals in human inflammatory diseases. AIMS Biophysics. 2017;4(4):596-614. [DOI:10.3934/biophy.2017.4.596]

29. Zeng Q, Jin HZ, Qin JJ, Fu JJ, Hu XJ, Liu JH, et al. Chemical constituents of plants from the genus Dracocephalum. Chem Biodivers. 2010;7(8):1911-29. [DOI:10.1002/cbdv.200900188] [PMID]

30. Weremczuk-Jeżyna I, Grzegorczyk-Karolak I, Frydrych B, Królicka A, Wysokińska H. Hairy 
roots of Dracocephalum moldavica: rosmarinic acid content and antioxidant potential. Acta Physiol Plant. 2013;35(7):2095-103. [DOI:10.1007/s11738-013-1244-7]

31. Fattahi M, Nazeri V, Torras-Claveria L, Sefidkon F, Cusido RM, Zamani Z, et al. Identification and quantification of leaf surface flavonoids in wildgrowing populations of Dracocephalum kotschyi by LC-DAD-ESI-MS. Food Chem. 2013;141(1):139-46.

[DOI:10.1016/i.foodchem.2013.03.019] [PMID]

32. Babbar N, Oberoi HS, Uppal DS, Patil RT. Total phenolic content and antioxidant capacity of extracts obtained from six important fruit residues. Food Res Int. 2011;44(1):391-6. [DOI:10.1016/j.foodres.2010.10.001]

33. Kaufman SS, Vanderhoof JA, Young R, Perry D, Raynor SC, Mack DR. Gastroenteric inflammation in children with ulcerative colitis. Am J Gastroenterol. 1997;92(7).

34. Hendrickson BA. Gastric inflammation as a feature of ulcerative colitis. J Pediatr Gastroenterol Nutr. 2003;37(3):228-9. [DOI:10.1097/00005176200309000-00005] [PMID]

\section{How to Cite This Article:}

Keshavarzi Z, Safari F, Alipour B, Khoshniat A, Azizi R, Vatanchian M et al . Antioxidant Effects of Methanol Extract of Dracocephalum kotschyi in Acetic Acid Induced Rat Colitis Model. J Adv Med Biomed Res. 2022; 30 (138): $39-46$

\section{Download citation:}

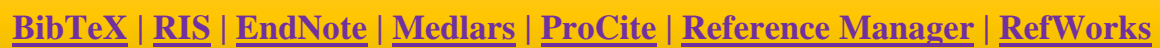

